Western University

Scholarship@Western

Department of Economics Research Reports

Economics Working Papers Archive

1996

\title{
A Model of Demand with Interactions Among Consumers
}

\author{
Robin Cowan \\ William Cowan \\ Peter Swann
}

Follow this and additional works at: https://ir.lib.uwo.ca/economicsresrpt

Part of the Economics Commons

Citation of this paper:

Cowan, Robin, William Cowan, Peter Swann. "A Model of Demand with Interactions Among Consumers." Department of Economics Research Reports, 9609. London, ON: Department of Economics, University of Western Ontario (1996). 
ISSN:0318-725X

ISBN:0-7714-1929-5

RESEARCH REPORT 9609

A Model of Demand with Interactions among Consumers

by

Robin Cowan, WilliamCowan and Peter Swann

June 1996

\author{
Department of Economics \\ Social Science Centre \\ University of Western Ontario \\ London, Ontario, Canada \\ N6A 5C2 \\ econref@sscl.uwo.ca
}




\title{
A Model of Demand with Interactions among Consumers*
}

\author{
Robin Cowan*, William Cowan** and Peter Swann*** \\ June, 1996.
}

\begin{abstract}
*University of Western Ontario, Canada and Ecole Nationale Supérieure de Telecommunications, Paris, France

** University of Waterloo, Canada

*** University of Manchester, UK
\end{abstract}

\begin{abstract}
The aim of this paper is to study emergent patterns of demand when there are social interactions between different consumers. Specifically, our concern is with the case in which consumers' preferences are influenced by the consumption behaviour of others. The analysis recognises three reference groups. The first is a peer group, of similar consumers, with whom the individual interacts on a regular basis, and with whom the individual desires to share some consumption activities. The second is one or several contrast group(s), with which the individual seeks actively not to interact, and from whom the individual wishes to distinguish himself/herself. The third is an aspirational group, with whom the individual does not interact on a regular basis, but wishes that he/she did, and with whom the individual would like to share consumption activities, but cannot. In this relatively simple model, these groups influence the individual's behaviour. The paper derives steady state and dynamic properties of the distribution of consumption over users. The degree to which consumption is restricted to a small group of similar agents is determined by the strength of the contrast and aspiration effects. These effects also drive the distribution away from the "natural" distribution, i.e. the one that would prevail were consumers to consider only the properties of the good, and not the actions of other consumers. The paper discusses the potential application of this modeling framework in a large number of consumption settings.
\end{abstract}

Keywords: Consumption, Evolutionary Theory, Interdependence, Externalities J.E.L. Codes: D11, D62

*We acknowledge helpful discussions with Cristiano Antonelli, Stan Metcalfe, Staffan Hulten, and Ulrich Witt, none of whom is responsible for any remaining errors. 


\section{Introduction}

This paper is a contribution towards an evolutionary theory of consumption. It studies the patterns of demand that emerge when there are social interactions between different consumers. In particular, it studies the case where consumers' preferences are influenced by the consumption behaviour of others. The analysis recognises three reference groups of consumers whose behaviour will influence an individual's preferences. The first is a peer group, of similar consumers, with whom the individual interacts on a regular basis, and with whom the individual desires to share some consumption activities. The second is a contrast group, with whom the individual seeks actively not to interact, and from whom the individual wishes to distinguish himself/herself. The third is an aspirational group, with whom the individual does not interact on a regular basis, but wishes that he/she did, and with whom the individual would like to share consumption activities, but cannot.

In this relatively simple model, these are the three groups who influence the individual's preferences. The effects of other groups' behaviour is assumed to be neutral. In some cases, for example where there are important consumption externalities from the widespread (but anonymous) consumption of a particular product or service, then the consumption behaviour of the anonymous mass might have an important positive effect on preferences. Conversely, where there is congestion in consumption, then the consumption behaviour of the anonymous mass may have an important negative effect on preferences. These two features are undoubtedly important in some settings. The first is recognized in the literature on the economics of standards. The second is in the literature on consumption of a finite resource. But in the present paper we do not consider effects of this sort. Rather it is the reaction to the consumption behaviour of specific reference groups that is of concern.

The structure of the paper is as follows. Section 2, recognizing that evolutionary models of production and the firm have contributed much to our understanding in that field, shows that there is an important need for an evolutionary theory of consumption to develop in parallel. Section 3 summarizes some of the main literature on consumption that recognises inter-dependencies between consumers and argues that this provides some important foundations for such an evolutionary theory of consumption. Section 4 then gives a very brief illustration of some of the very many empirical demand questions for which this sort of evolutionary analysis of would be relevant. Following the lead identified in Section 2, Section 5 describes the model used in this paper and Section 6 illustrates some 
of the results graphically. Section 7 discusses the possibility of broadening the setting of the model and the possibility of clustering in consumption behaviour, suggesting that the modeling of clusters and inter-dependencies in consumption has much in common with the modeling of clusters of production activity (Cowan and Cowan, 1995, David and Foray, 1995).

\section{An Evolutionary Approach to Consumption}

Evolutionary models are now accepted as one of the most useful ways of thinking about how to model firm behaviour. (See Nelson 1995, for a recent review, and for a more cautionary view, DeBresson, 1987.) In terms of their contribution to the understanding of innovation, these models place great emphasis on the importance of localized knowledge. The literature recognises of course that knowledge can be localized along many different dimensions: geographic space, product characteristics, technological competence, and so on. Firms search for new things near the things that they know and do well, in other words there is a tendency for a firm to stay on a technological trajectory that has worked for it in the past (Dosi, 1982). Similar concerns emerge in the process of innovation in the sense that an innovating firm is constrained by its current set of competencies, but also by its current set of linkages with for example, the suppliers of its inputs, and the distributors and consumers of its product (Silverberg et al. 1988; Metcalfe and Gibbons, 1986). Thus we observe the co-evolution of firms with their industries, other industries and institutions. These concerns have been developed into a rich set of models of firm behaviour and industry evolution.

At a macro level, the emphasis of this evolutionary literature is on self-organization and the emergence of structure. One much studied example of this is in the literature on choice of technology or standardization. In this literature, models have been developed to examine the way in which choices by individual agents result in a coherent structure in the distribution of technologies. Initially, the literature was concerned with standardization in quite a narrow sense (see for example, Arthur (1989), Cowan (1991), David (1985), or Farrell and Saloner 1985). But more recently, the literature has broadened to concern itself with the spatial characteristics of technological distributions-see Cowan and Cowan (1994, 1995), and David et al. (forthcoming). In all of these models, agent interactions, either in the form of pecuniary or non-pecuniary externalities, serve to organize the choices of individual agents, and to produce and reinforce structure in their patterns of behaviour. Again, these models are both path-dependent and evolutionary in that changes are incre- 
mental, and that current motion in the system is highly constrained by the its previous path.

Related to this work on firms and technology is work on the development and change of institutions seen from an evolutionary perspective-Schotter (1981), David (1992). Again, the central idea in this literature is that institutional change is constrained by the current state of the institution itself, and the current state of things to which it is linked. Thus an institution will typically change incrementally, and certain aspects of it may harden, and become difficult to change.

While there has been considerable work on the evolution of the production side of the economy, and institutional development, there has as yet been very little comparable work on the evolution of consumption. There is, in fact, no mention of it in Nelson's recent survey of evolutionary theorizing about economic change (Nelson, 1995). There is a limited amount of work on conformity and fad behaviour (for example, Bernheim, 1994), and also some work on pattern formation in consumption (Granovetter and Soong, 1986). Moreover, some of the contributions to analysis of technology standards (notably Farrell and Saloner, 1985) recognises that standards emerge because there are, in effect, economies of scale in consumption. And there are some recent contributions towards an evolutionary analysis of consumption from Keilback (1995), Kwasnicki (1995), Feichtinger et al. (1995), and Weise (1992). But overall the literature is limited, and while Section 3 summarizes some of the other literature that can provide the foundations for an evolutionary theory, most of it is not really cast in a evolutionary framework.

We also note that attempts to integrate the evolutionary analysis of production and consumption are almost non-existent, and this paper does not correct this deficiency. There are few (if any) evolutionary models which investigate production and consumption simultaneously. This is a serious shortcoming of the evolutionary approach to economic change, since it is clear that both sides of a market are equally important, and that both sides must evolve together if the market is to work at all. In many markets, in fact, change in the demand side is a major determinant of change on the supply side, and vice versa. One study that moves us some way in this direction is by Pasinetti (1981, esp. chapter 4).

There are of course conditions under which production and consumption can be treated independently of one another, as has been the case in evolutionary models of production. 
The salient issue is one of time scale. If, for example the production side of the market is changing very slowly relative to the consumption side, then changes in production can be treated simply as exogenous shocks. Or, in contrast, if the production side is changing rapidly, those changes can be treated as noise-for examples of models where these approaches are used explicitly, see Cowan and Cowan (1994), Weidlich and Braun (1993). In short, if the time scales of the two sides of the market are very different, then partial equilibrium models are appropriate. If the time scales are similar, however, a general equilibrium approach will be necessary to gain a full understanding of market dynamics.

We examine in Section 4 of the paper a number of examples which cannot be adequately described in an equilibrium model with rigidly fixed tastes. This does not mean that we have to assume that tastes are inherently and indefinitely mutable. But the objective of this paper is to examine how some very simple sources of path dependence in preferences can lead to a rich set of patterns of consumption.

\section{Consumption with Inter-dependencies: The Traditional Literature}

In most of the economic analysis of consumption, tastes are generally treated as exogenous, and hence taste changes are essentially random, except where they relate to changing preferences over the life-cycle, simple habit formation or differences due to socio-economic and family composition factors.

One obvious exception, most thoroughly developed in marketing, is the observation that tastes can be modified by advertising and other promotional activity on the part of producers. For some writers this is perhaps one of the main reasons why tastes change. Galbraith (1958) demonstrated how needs can be created by skillful advertising. Packard (1957) spoke of the 'hidden persuaders' who convince the consumer of his or her need for a product. While these effects are undoubtedly important in some situations, this will not be the focus of our attention in this paper. Rather, we are concerned with the reasons why tastes may change as a result of the individual's own consumption behaviour, and that of other people, and not because of any exogenous effects or the actions of an extraneous agency. Another important and related literature in marketing is on the evolution of distribution (Filser, 1987), drawing on the pioneering work by Alderson (1957, 1965). Recent contributions have suggested that this may have a lot to teach the economic analysis of industrial organization (Priem, 1992). 
In economic analysis, the factors influencing demand can be grouped into four broad groups:

1: price and product attributes;

2: socio-economic attributes of the buyer (including income);

3: the consumer's own past consumption history;

4: consumption patterns of the consumer's peer group and rivals, etc.

The main body of modern economic analysis has been rather successful at studying factors 1 and 2. Factor 3 is examined in the analysis of habit formation in consumption. But within modern economics there have been few attempts to tackle question 4 , except in the context of network externalities, and even fewer attempts to treat the concept of distinction in consumption.

Having said that, the idea that tastes for particular consumption goods or activities are endogenous in general and related to the behaviour of others is an old one, if still rather underdeveloped. Adam Smith recognized "the chief enjoyment of riches consists in the parade of riches" [Wealth of Nations, Book 1, Chapter 11, Part 2]. The idea of conspicuous quality can be found also in Marshall, who recognized that with every step of his ascent, man requires not just greater quantities of goods, but an increase in the quality of goods consumed. And moreover, "strong as is the desire for variety, it is weak compared with the desire for distinction" [Marshall, 1920, Book III Chapter ii, Section 1]. But it was Veblen (1899) who was first to develop a major theory of conspicuous consumption: in this, consumption is an activity undertaken to create an impression rather than to satisfy needs. The tastes of the rich individuals are clearly dependent on the consumption activities of others. Conspicuous consumption requires that individuals indulge in consumption activities recognized by their peers. But it also requires that they distinguish their consumption from that of ordinary people. At once then, there are reference to the peer group and the anonymous masses. And indeed, it is not enough that consumption simply imitates that of the peer group: there must be imitation and innovation, so that the individual occupies a distinctive place in the group.

While the apex of conspicuous consumption observed in turn of the century USA, of which Veblen spoke with such disdain, has not perhaps been seen again, it would be wrong to think of it as a transitory phenomenon. As Galbraith (1987) points out, conspicuous 
consumption in the form of adornment is found equally in primitive societies. Nor, as Galbraith (1987, p.174) stresses, does superiority come uniquely from conspicuous consumption: following Veblen, the "impecunious intellectual (could) feel socially superior to the man of means". Leibenstein (1950) summarizes these effects in a famous paper.

One of the best known contributions in economics to the analysis of consumption patterns is the work of Duesenberry (1949). He recognized that there is inertia in consumption: when incomes fall, families run down savings to maintain the standard of consumption to which they have become accustomed. A pioneering econometric contribution was that of Brown (1952) who analyzed habit formation in demand behaviour as a positive autoregressive components in a traditional demand model. There have been some important subsequent contributions on the endogeneity of preferences (for example, Becker and Murphy, 1988; Donckner and Feichtinger, 1993; Gorman, 1967; Gintis, 1974; Pollak, 1970; Steedman, 1989; von Weizaecker, 1971). Some empirical studies of trade and consumption have also shed light on these questions-for example, Hirsch(1977). It is also important to recognize here the literature on diffusion of innovations. Following the pioneering studies of Rogers $(1962,1983)$ and Mansfield's (1961) "epidemic" model, has recognized that new diffusion depends on new consumers being exposed to other consumers who have already bought. While this doesn't imply an interdependence of preferences, it does indicate correlation in consumption patterns.

One of the major recent contributions to our understanding of inter-dependence in consumption patterns is the literature on path dependence (Arthur, 1989; David, 1985). Moreover, the the literature on network externalities (Katz and Shapiro, 1985) and de facto standards (Farrell and Saloner, 1985) demonstrate that there are economies of scale in consumption so that consumers benefit from being part of a large network of users. This is also recognized by Gaertner (1974).

In some core areas of economic theory (for example Dasgupta and Stiglitz, 1980), it is recognized that individual consumers can have a demand for variety. While the origin of this demand for diversity is not developed in detail within that literature, nevertheless it can be interpreted in the current context as a desire on the part of the consumer to differentiate his or her current consumption patters from his or her previous consumption history. 
Other important contributions to a richer evolutionary theory of consumption come from outside the mainstream of economics. Fine and Leopold (1993) compare economic, sociological and psychological approaches to consumption. The sociology of consumption (Douglas, 1975; Granovetter, 1978; Bourdieu, 1984) has made much more progress in recognizing the social and interdependent nature of consumption. In Bourdieu's analysis (1984), taste is driven in part by the desire for distinction and peer group reference, and that gives rise to an explicitly evolutionary character to consumption patterns. But this last theory lacks the power of an quantitative modeling framework which an evolutionary economic theory of consumption can bring.

\section{Empirical Examples}

This section does not attempt a rigorous empirical analysis, but gives some simple illustrations of some of the many contexts in which consumption patterns are independent. We have not attempted to groups these under the headings, association, distinction and aspiration because in many cases there are associative, distinctive and aspirational aspects to consumption behaviour.

One of the most obvious examples of inter-dependencies in consumption is in the market for holiday resorts. Some holiday makers seek resorts where they can be with chosen friends or peer groups. Some seek to keep away from the masses in popular (and down-market) resorts. Some seek to take holidays where they brush with the rich and famous. The rich and famous in turn may wish to move away from the vulgar arrivistes. These patterns of differentiation and association make for an interesting dynamic indeed. We may observe, for example, cyclical popularity in holiday resorts. A number of patterns may be observed, with the following as one possibility. A new resort may start off as a distinctive and select venue, it then starts to become vulgar in the eyes of the pioneers as it grows in popularity, and then goes distinctly down market-which drives out more of the early customers. In short, demand is dynamic because demand patterns today depend on the history of demand. Moreover there are some clear inter-dependencies between the demand patterns of different groups.

Another obvious area of interdependence in consumption, which borders closely on the analysis of interdependence in production, is the emergence and decline of different areas of a city. Some of the (now) most fashionable areas of London (say) were very down at heel earlier this century. Then the areas became fashionable, first amongst bohemians (artists 
and the like), and then amongst the fashionable associates of these. Chelsea (London) is one of the more striking examples. Or working in the other direction, ghettos can form out of formerly respectable areas (Durlauf, 1994; Schelling, 1971). If some middle class families leave and are replaced by poor families, then others will start to leave and so the process continues. This process is of course very close to the concept of clustering in production. Vibrant clusters form because of externalities in co-location, while moribund clusters decay when they are populated by old industries generating few positive externalities and many negative externalities.

The social experiments of the 1980 s generated consumption cycles that fit nicely with this framework. Some makes of sports car were synonymous with 'yuppy' success, and the ownership of this hardware was a sure signal of membership of the peer group. By the mid nineteen nineties, in contrast, the strong association of these cars with a group from which many wish to distinguish themselves has lead to a decline in the second-hand values of such machines.

With network technologies (such as fax, e-mail, mobile phones, and so on), the generally positive network externalities lead to positive correlations in consumption patterns. Here indeed, it might be thought that it is the consumption of the anonymous mass of consumers that generates network externalities, rather than the specific groups identified in Section 1 of the paper. But on reflection, this indifference to the identity of other consumers is unlikely. As Swann (1996) shows, each individual has a particular network with whom he wishes to communicate, and it is the diffusion of the technology to members of that network that generates externalities, and not the random diffusion amongst anonymous members of the public.

When we talk of technologies where network externalities are indirect (such as in computer software, hi-fi CDs, and video software), then network externalities might in some cases be proportional to the number of adopters, irrespective of their identity. Thus, for example, the purchaser of a software package with a large installed base can be confident that this package will continue to be supported by the producer, and this is the network externality he looks for. The identity of the other users in this installed base is generally unimportant. Even then, however, it is likely that the user will care about what sorts of users they are, and in particular whether they are making similar use of the package. If 
so, then the user can expect to receive support for the sorts of software applications he wishes to make; if not, then this may be more problematic.

In short, in the context of network technologies, the size of these network externalities are likely to depend on who is in the network. If the "right" people are in the network, then the externalities are large; but if the wrong people, then the externalities are negligible.

In some cases, indeed, it is possible that having the wrong people in the network may actually reduce the value of the technology. This could happen if the "wrong" users simply lead to congestion in the network, and bring no compensating benefits. Alternatively, such effects could arise because consumers wish to distinguish themselves from these "wrong" users. Thus for example, some have suggested that the association of the mobile phone with "yuppy" users has lead some other consumers to shun the device. In this case, consumption preferences are inversely related to the consumption behaviour of the distinction group.

Consumption of another broad category of products is intensely social, for example: film and television viewing behaviour; the choice of other entertainment; magazine circulation; the value of fashion clothing; the popularity of chart hits. Habit formation is an important phenomenon in television viewing (Swann and Tavakoli, 1994). Here, moreover, there are obvious peer groups with whom consumers choose to associate themselves, other groups from which the powerfully wish to distinguish, and aspirational role models too. Moreover, there are obvious cycles of popularity with these items, similar to those observed in the case of holiday resorts above. The pioneers select an innovative new product for consumption, and their peers follow. In due course those who aspire to join this elite follow, but the pioneers do not like being copied by groups from whom they have sought to distinguish themselves. The pioneers then turn away from these (now) common preferences, and seek to distinguish themselves once again by innovation in consumption.

The popularity of Christian (or given) names can show the same cycles of popularity. The elite choose distinctive names, that are in turn used by the lower orders, who aspire to join the elite. Again, the elite become unhappy with this process of popularization which turns the distinctive into a commonplace. Once again, innovation in consumption is required. 
A final example of the intriguing path-dependency of social processes of consumption can be found in the comparative diffusion of satellite TV and cable TV. The former is conspicuous (because of the aerial) while the latter is inconspicuous. If, as has been the case in some countries, satellite TV is at an early stage positioned as a lower middle class consumption activity, then the middle classes who wish to avoid the contempt of their middle class (geographical) neighbours will be reluctant to indulge in the conspicuous activity of viewing satellite TV. They may however be willing to indulge in the less conspicuous activity of subscribing to cable TV. But had satellite TV been positioned in a different up-market segment from the start, then middle class uptake of satellite TV might have been more rapid, because it would not have represented an activity from which this group wish to distinguish themselves.

These are only a selection of illustrative examples, but they do serve to motivate the model that follows.

\section{A Model of Inter-dependencies in Consumption}

In this section we present a very simple dynamic model of demand for a single good. It is a partial equilibrium model in which a single market is examined in isolation from other markets. We consider a population of heterogeneous consumers and are concerned with the distribution of consumers over the good. Thus the question at issue concerns not the price of the good, but rather who consumers it. In the model consumers are incompletely specified; in fact we consider only a scalar representation. Because we know that consumers are more complex than any scalar representation, this implies that we can only discuss the probability that an agent consumers a good. Schematically, the model works as follows. A good appears at time zero, and there is an initial distribution of agents consuming it (the source of this distribution is unspecified). How does this distribution evolve over time, and what is the final distribution? We address this question at the level of the agent. How does the probability that an agent consumes the good change in time? There are two factors that impinge. First, any good has objective qualities-a resort has certain types of hotels, beaches or not, chamber music or not and so on. Considering only these facts, an agent of type $s$ has a probability $p_{0}(s)$ of consuming the good. Each period involves a partial adjustment towards $p_{0}(s)$. But there is a second effect, namely the aspiration and distinction effects discussed above in section 3 . The probability that an agent consumes the good changes depending on whether the distribution of users of the good is is changing towards the aspiration group or the distinction group. Rather than 
specifying specific agents are members of the reference groups, we use a function, $F(\cdot)$ which measures externalities in consumption, to define these groups implicitly. These two considerations generate a differential equation for the probability that an agent of type $s$ consumers the good. We solve this equation to generate both steady state results and results about the dynamics of adjustment to it.

Consider a large population of agents each identified (non-uniquely) by a scalar $s$, distributed over the real line. This is an incomplete representation of an agent, in that it is insufficient information to predict his behaviour, which implies that we can make only probabilistic statements about it. We will refer to $s$ as "social status", and assume that it is unchanging over time. ${ }^{1}$ At time zero a good appears. Initially the probability that an agent consumes the good is given by $p(s, 0)$ where $s$ is the agent's social status. The genesis of this original probability is unspecified. The probability changes over time, however, according to the differential equation

$$
\frac{d}{d t} p(s, t)=\int_{-\infty}^{\infty} F\left(s, s^{\prime}\right) p\left(s^{\prime}, t\right) d s^{\prime}-\alpha\left(p(s, t)-p_{0}(s)\right) .
$$

The second term in this equation reflects a partial adjustment of the agent's current probability of consumption towards the probability that would prevail were he to consider only the objective properties of the good, that is, $p_{0}(s)$. We assume here that there is a correlation between the parameter $s$ and the taste of the agent for the objective qualities of the good. There is a correlation between social status and tastes for different types of leisure activities, so resorts, say, offering different types of leisure activities will, probabilistically, fit better with the preferences of different social groups. This correlation is a determining factor of the distribution $p_{0}$. The parameter $\alpha$ measures the strength of the attraction of the objective qualities of the good relative to the strength of the externalities represented by the first term. The first term captures externality effects. The function $F\left(s, s^{\prime}\right)$ measures the degree to which the consumption by an agent of type $s^{\prime}$ makes the good attractive to an agent of type $s$. Of course $F(\cdot)$ can be positive or negative.

1 We use the term "social status" as it fits well with the sociological literature on demand determination. This single dimension of heterogeneity could as easily be income, education,... That the model uses a scalar to describe agents indicates that they are quite incompletely specified. Agents can be more completely specified by increasing the dimension of $s$. In principle the analysis is identical, (provided that there is always some incompleteness in the specification, as seems likely) but has the cost of considerable notational and analytical inconvenience. 
The interaction term, $F\left(s, s^{\prime}\right)$, can always be written as a sum of two functions: $F\left(s, s^{\prime}\right)=F_{0}\left(s-s^{\prime}\right)+F_{1}\left(s, s-s^{\prime}\right)$. We will assume that $F_{1}\left(s, s-s^{\prime}\right)=0$. This assumption has implications regarding the extremes of the distribution of agents. Virtually all sources of heterogeneity that might impinge on consumption decisions have finite support. There is a richest person in the world, and his income or wealth is finite. For agents near the extremes of the support of the heterogeneity, (those with large or small $s$ ) $F_{1}$ will differ from that of those away from the extremes. Because the richest person has no one above him, there will be boundary effects which must be taken into account. The reaction of the richest person to the fact that he is on a boundary will in general be visible for a certain distance away from the boundary, as his "altered" behaviour will affect the behaviour of those just beneath him in wealth. (Similarly for the poorest person.) In this paper we will not make any attempt to incorporate this sort of effect, which must be done through $F_{1}$, so are thus restricting our attention to agents away from the extremes of the support. This can be seen as equivalent to assuming unbounded support.

Solving equation 1 is done by transforming both $s$ and $t$. (See the appendix for details.) A Fourier transform on $s$ and a Laplace transform on $t$ generate the conjugate variables $k$ and $z$ respectively. We call the distribution of the transformed variables $P(k, z)$, so that $P(k, z)=\int_{-\infty}^{\infty} e^{-i k s} \int_{0}^{\infty} e^{-i z t} p(s, t) d t d s$. Following the derivation in the appendix, we can write the solution in terms of $k$ as

$$
P(k, t)=\frac{\alpha P_{0}(k)}{\alpha-F_{0}(k)}-\frac{\alpha P_{0}(k)-\left(\alpha-F_{0}(k)\right) \mathcal{P}(k, 0)}{\alpha-F_{0}(k)} e^{-\left(\alpha-F_{0}(k)\right) t}
$$

where $F_{0}(k)=\int_{-\infty}^{\infty} e^{-i k s} F_{0}(s) d s$ and $P_{0}(k)=\int_{-\infty}^{\infty} e^{i k s} p_{0}(s) d s$

We leave the solution in terms of the transformed variable, $k$, as the solution remains much more transparent than it does when written in terms of $s$. Large values of $k$ should be interpreted to indicate the response of an agent to nearby agents, whereas small values of $k$ are interpreted as the response of an agent to the actions of the entire social hierarchy. In the context of our model, this solution has five interesting properties which we state as propositions. The first two propositions deal explicitly with the steady state solution.

Proposition 1: In the absence of inter-consumer interaction the equilibrium probability of type $s$ consumes the good is $p_{0}(s)$. 
This follows trivially from equation 2 , by setting $F(\cdot)=0$ and letting $t$ go to $\infty$. If the system has a stationary state (that is, if $\alpha-F_{0}(k)>0$ ), then the second term goes to zero. The result follows intuitively from the second term of equation 1 , the partial adjustment towards the "natural" distribution.

Proposition 2: The equilibrium probability changes in a non-trivial way when interconsumer interaction is present. The actual equilibrium probability deviates from the "natural" probability according to

$$
\lim _{t \rightarrow \infty} \mathcal{P}(k, t)=\alpha P_{0}(k) /\left(\alpha-F_{0}(k)\right)
$$

where again $F_{0}(k)=\int_{-\infty}^{\infty} e^{i k s} F_{0}(s) d s$ and $P_{0}(k)=\int_{-\infty}^{\infty} e^{i k s} p_{0}(s) d s$

This is a re-arrangement of equation 2, and follows from the Appendix.

Both propositions one and two deal with the steady state of the system. Propositions 3 to 5 deal with the path to the steady state solution.

Proposition 3: When $F_{0}\left(s-s^{\prime}\right)$ is an even function (consumers react identically to those higher and lower in the status distribution, $F\left(s-s^{\prime}\right)=F\left(s^{\prime}-s\right)$ ) the dynamic behaviour of the probability distribution is strictly diffusive: the initial state spreads continuously in status and decays exponentially while the equilibrium state builds up exponentially.

This can be seen by examining equation A4 in the appendix. It can be re-arranged to write

$$
\begin{aligned}
\mathcal{P}(k, t) & =\frac{\alpha P_{0}(k)}{\alpha-F_{0}(k)}\left(1-e^{\left(\alpha-F_{0}(k)\right) t}\right)+\frac{\left(\alpha-F_{0}(k)\right) \mathcal{P}(k, 0)}{\left(\alpha-F_{0}(k)\right)} e^{\left(\alpha-F_{0}(k)\right) t} \\
& =\frac{\alpha P_{0}(k)}{\alpha-F_{0}(k)}\left(1-e^{\left(\alpha-F_{0}(k)\right) t}\right)+\mathcal{P}(k, 0)\left(e^{\left(\alpha-F_{0}(k)\right) t}\right) .
\end{aligned}
$$

An even valued function $F_{0}(s)$ means that the exponent $\alpha-F_{0}(k)$ is real valued. Thus any intermediate state can be written as a sum of the decaying initial state and the growing final state. (In general, the initial state changes shape as it decays and the final state changes shape as it grows.) 
We can illustrate the intuition behind this proposition in the following way. Consider a function $g(s)$ that simply shrinks or grows in time. That is, $g(s, t)=e^{a t} g(s, 0)$. Transform $s$ to $k: G(k)=\int e^{-i k s} g(s) d s$. Now include explicitly the time dependence: $G(k, t)=$ $\int e^{-i k s} g(s, t) d s=\int e^{-i k s} e^{a t} g(s, 0)=e^{a t} \int e^{-i k s} g(s, 0)$ which is the form of equation 3.

Proposition 4: When $F_{0}\left(s-s^{\prime}\right)$ is an odd function (consumers react inversely to those higher and lower in the status distribution, $F\left(s-s^{\prime}\right)=-F\left(s^{\prime}-s\right)$ ) the dynamic behaviour of the system consists of travelling waves (peaks in the distribution that move in status with time), damped by $\alpha$, the term representing the speed of adjustment toward the "natural" state.

This proposition follows from the following basic property of Fourier transforms. Consider a function $g(s, t)$ that is a simple travelling wave, so that $g(s, t)=g(s+$ $v t, 0)$. Transforming $s$ in period $0: G(k, 0)=\int e^{-i k s} g(s, 0) d s$. In period $t, G(k, t)=$ $\int e^{-i k s} g(s+v t, 0) d s$, which, by the change of variables $s^{\prime}=s+v t$ becomes $G(k, t)=$ $\int e^{-i k\left(s^{\prime}-v t\right)} g\left(s^{\prime}\right) d s^{\prime}=e^{i k v t} \int e^{-i k s^{\prime}} g\left(s^{\prime}\right) d s^{\prime}=e^{i k v t} G(k)$ which is exactly the form of equation A4 if $F_{0}(s)$ is odd, since in that case $F_{0}(k)$ is imaginary.

Proposition 5: All functions $F_{0}\left(s-s^{\prime}\right)$ can be written uniquely as sums of even and odd functions. When $F_{0}\left(s-s^{\prime}\right)$ contains both even and odd functions non-trivially, the solution is the sum of two solutions having the behaviours described in Propositions 3 and 4. The qualitative features of this solution depend on the detailed form and value of the different parts.

These propositions are illustrated graphically in the next section.

\section{Four Illustrations}

This section contains illustrations of the first four propositions of the previous section. Figure one shows the simplest case, corresponding to Proposition One. Here there are no externalities in consumption, and agents decide whether to consume based solely on the properties of the good. As there is an assumed correlation between social status and taste for particular properties, this generates a 'natural' distribution over social status. The initial distribution of consumers, after the appearance of the good, is shown with a dotted line, the final, 'natural' distribution is shown with a a solid line. These two distributions serve as the base case for the other figures. 
In the figures, on the abscissa is an arbitrary measure of social status, running from 0 , which is the highest status, to 500 , the lowest. The ordinate measures the probability that a person of a given status will consume the good. The arbitrary initial condition is a distribution of the probability that a person of a given social status will consumer the good: a gaussian distribution having a mean value of 100 . In the four different cases, $F_{0}\left(s-s^{\prime}\right)$ is taken from the same family of functions. The important feature of this family is that it contains functions that increase and then decrease (in absolute value) with $\left|s-s^{\prime}\right|$. That is, that consumers are affected by people of some distance above and below them in social status, but ignore the behaviour of very distant people.

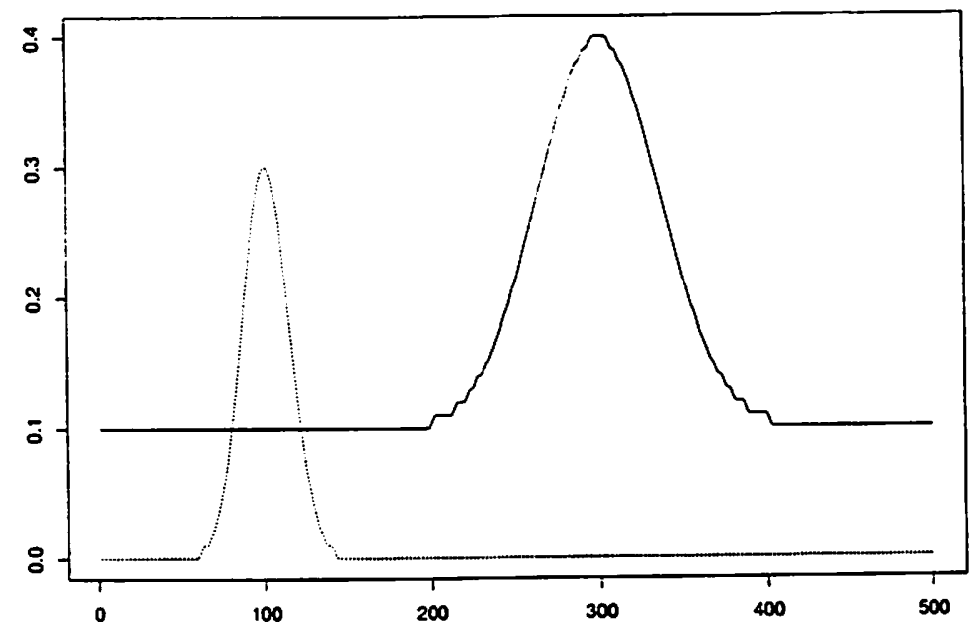

Figure 1: No Externalities in Consumption

Figure two illustrates the changes that occur when externalities in consumption are present. $^{2}$ In this figure, an aspiration group exists, as does a distinction group. Thus consumers try to imitate those above them in social status, and distinguish themselves from those below. The final distribution is distorted from the natural one. Mass is distributed over more social states, and the peak is less pronounced. For these parameter values, the distribution in fact has two modes, though the mode nearer the mode of the 'natural' distribution is more pronounced. The mode here is shifted to the right, as consumers are

2 In figures two and four, there are effects at the ends of the abscissa that stem from the boundary considerations discussed above. These should be ignored while interpreting the figures as illustrations of the propositions, since, as discussed above, the model refers only to the interior of the distribution. 


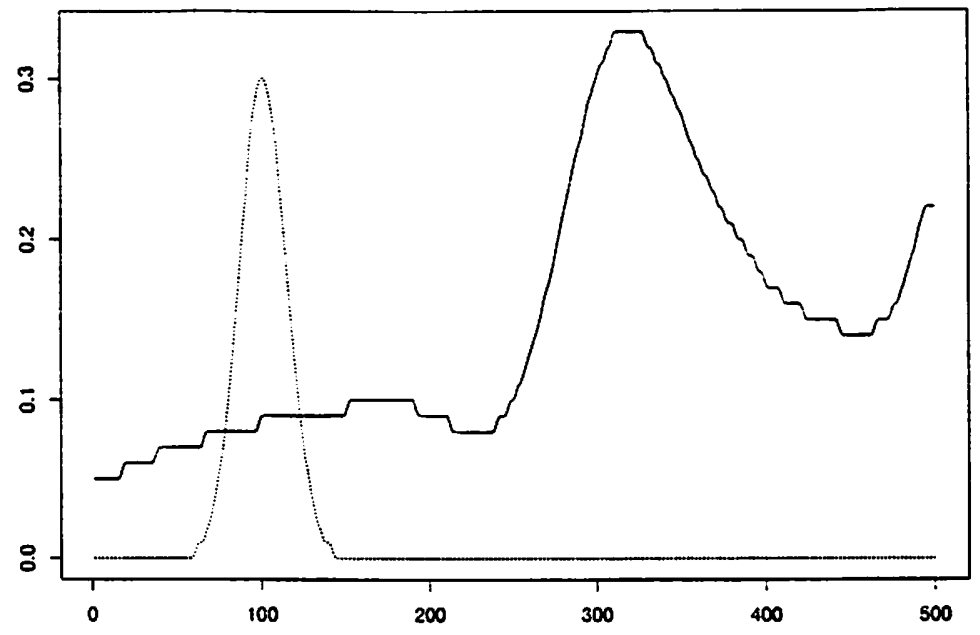

Figure 2: Distinction and Aspiration Effects

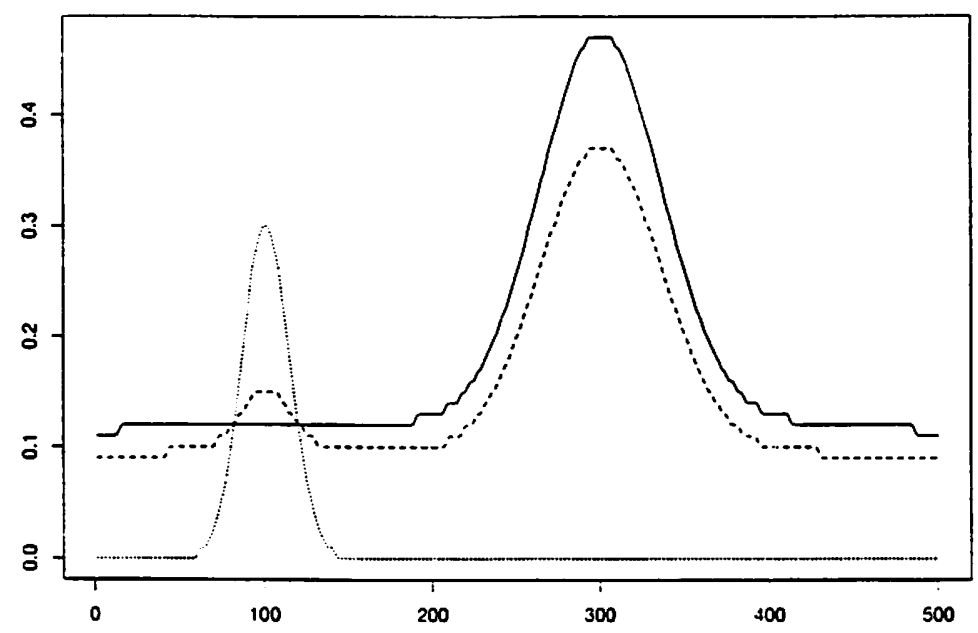

Figure 3: Symmetric Externalities from Nearby Consumers, $F(\cdot)$ is even.

trying to move away from those below them. At the same time the peak is broader and flatter, as there is more mass away from its modal value.

Figure three illustrates the dynamics of the system when $F(\cdot)$ is even, that is, when externalities are symmetric in the social space. Consumers gain positive externalities from those both above and below them, but the strength of the externality diminishes with distance. Again, the initial distribution is shown with a dotted line, the final distribution 
in a solid line, and one intermediate distribution in a dashed line. Here we can observe that over time the peak seen in the initial distribution shrinks, and the peak seen in the final distribution grows, both of them slowly spreading the while. But as is stated in the proposition, the modal values of the distribution do not change over time.

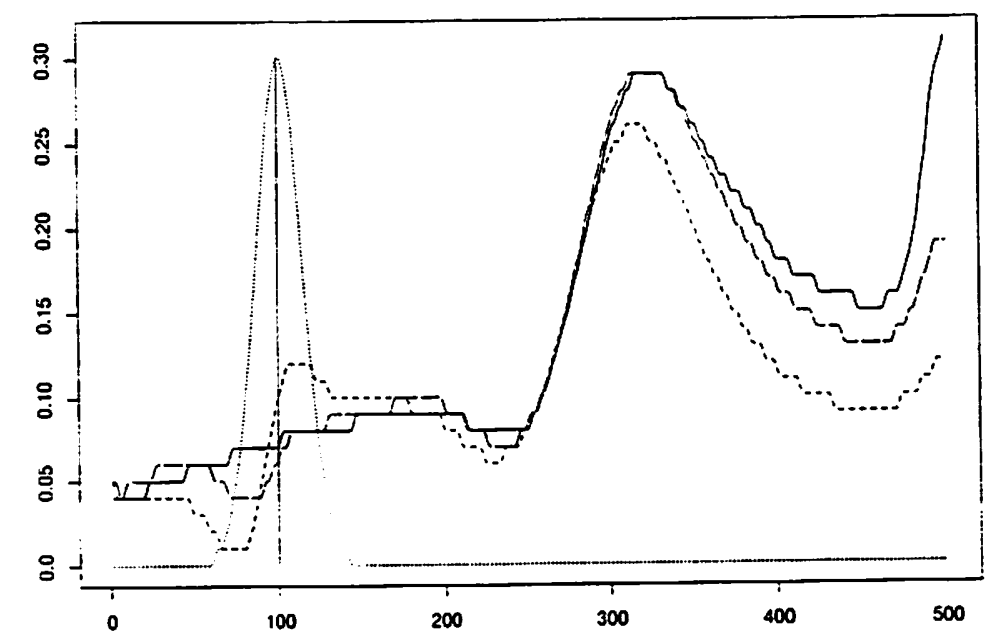

Figure 4: Distinction and Aspiration Effects, $F(\cdot)$ is odd.

Figure four includes two intermediate cases, the first being the shorter dashed line, the second being the longer. ${ }^{3}$ In this illustration $F(\cdot)$ is odd. That is, agents receive positive externalities from having behaviour similar to those above them and negative externalities from having behaviour similar to those below them. The unique mode of the initial distribution is at about 100 , indicated by a vertical line. The earlier intermediate distribution shows a trough below 100 , and a peak at about 110, a second trough at about 230 and a second, more important peak at about 310 . The second intermediate state (the longer dashed line) shows a less deep trough at about 80, a less high peak at 190, a less deep trough at 235 and a second peak at 315 . The final distribution shows a peak at 180 , a trough at 235 , and the major mode at 320 . What we see then is that the distribution is, as in the case of figure two, in general spreading out. But the spreading process involves a wave of consumption that moves to the right, bringing a trough behind it. But as the wave travels, it diminishes in height, and spreads.

\footnotetext{
3 Again, boundary effects in this figure should be ignored.
} 


\section{Discussion-clustering}

The formal model is a model of a single good, and no attempt has been made here to deal with the more complex case in which consumers are faced with the choice among several goods. That case, however, has similarities with other models in the literature dealing with the location of economic activity. We can think of goods as occupying locations in product characteristic space in as in the work of Prescott and Vischer (1977). If that space is crossed with social status space, over which our parameter $s$ is defined, we produce a space in which we can observe the distribution of status over products. The setup now resembles those used in multi-dimensional location models with the qualification that one of the dimensions (the status dimension) may have different dynamic considerations than the others.

Clustering of activity is a very common behaviour in these models, though the precise form that the clustering takes is very specific to the details and parameter values of them. Positive externalities in consumption imply that consumers locate near each other in product space. There will be clusters of products with high demand, surrounded by, or side by side with, products having low demand. This result appears in models of industrial location (Arthur, 1991), product characteristics (Prescott and Vischer, 1977) or R\&D location (Cowan and Cowan, 1996, forthcoming). It is worth noting a fundamental result, due to Archibald and Rosenbluth (1975), and applying to product competition, which is that as the dimensionality of the space increases the number of neighbours of an agent or product increases rapidly. The implication here is that in a high dimensional space, consumers may cluster in a wide variety of ways. Finally, the possibility of endogenous movement of clusters might arise from aspiration and distinction effects in the status dimension. The interaction between movement generated in this dimension and the stability of the clustering in other dimensions is an effect yet to be worked out.

\section{Conclusions}

This paper has explored what patterns of demand emerge when there are social interactions between different consumers. We concentrated our attention on the case where consumer preferences are influenced by the consumption behaviour of three reference groups: a peer group of similar consumers, with whom the individual shares some consumption activities; a contrast group (or distinction group), from which the individual wishes to distinguish him or herself; and an aspirational group, with whom the individual would like to share consumption activities, but cannot. The paper showed how this structure evolves 
over time and the nature of the state toward which it tends. The tension between the objective properties of the good, and the externalities in consumption determine the final distribution of consumption over the attributes of agents. The nature of the externalities determines the properties of the evolution toward that state. The paper showed briefly that this model could have a wide range of applications. The relevance and potential applications of this model was demonstrated by a number of illustrative examples. While these were only suggestive, and not rigourously researched, they suggest that consumer preferences are frequently influenced by at least one of the three reference groups, and that the patterns of consumption generated in the simulations are frequently found in practice. 


\section{References}

Alderson W. (1957) Marketing Behaviour and Executive Action, Homewood, Illinois: R.D. Irwin Inc.

Alderson W. (1965) Dynamic Marketing Behaviour, Homewood Illinois: R.D. Irwin Inc.

Archibald G.C. and G. Rosenbluth (1975) "The 'New' Theory of Consumer Demand and Monopolistic Competition' Quarterly Journal of Economics, 89, 569-590

Arthur W. B. (1989) "Competing Technologies, Increasing Returns, and Lock-In by Historical Events' Economic Journal, 99, 116-131

Arthur W.B. (1991) "Silicon Valley Locational Clusters: Do Increasing Returns Imply Monopoly?" Mathematical Social Sciences, 19, 235-51

Becker G.S and K.M. Murphy (1988) "A Theory of Rational Addiction" Journal of Political Economy, $96,675-700$

Bernheim D. (1994) "A Theory of Conformity" Journal of Political Economy 105, 841-877.

Bourdieu P. (1984) Distinction: A Social Critique of the Judgement of Taste London: Routledge Kegan Paul

Brown T.M. (1952) "Habit Persistence and Lags in Consumer Behaviour" Econometrica $20,355-71$

Cowan R. (1991) "Tortoises and Hares: Choice Among Technologies of Unknown Merit" Economic Journal, 101, 801-814

Cowan R. and W. Cowan (1994) Local Externalities and Spatial Equilibria: On the Nature and Degree of Technological Standardization Research Report \#9421 Department of Economics, University of Western Ontario 
Cowan R. and W. Cowan (1995) Spatially Dependent Interactions: A Statistical Approach to Spatial Equilibria, Technological Standardization and Variety Research Report \#9507 Department of Economics, University of Western Ontario

Cowan R. and W. Cowan (forthcoming) "Quality Differentials and the Location of R\&D", Economics of Innovation and New Technology, 5(1)

Dasgupta P. and J. Stiglitz (1980) "Uncertainty, Industrial Structure and the Speed of R\&D" Bell Journal of Economics, 11, 1-28

David P. A. (1985) "CLIO and the Economics of QWERTY" American Economic Review, $75,332-336$

David P.A. (1992) Why Are Institutions the 'Carriers of History'?, Unpublished Paper, All Souls College, Oxford

David P.A., D. Foray and J.-M. Dalle (forthcoming) "Marshallian Externalities and the Emergence and Spatial Stability of Technological Enclaves". Economics of Innovation and New Technology, 5(1)

DeBresson C. (1987) "The Evolutionary Paradigm and the Economics of Technological Change" Journal of Economic Issues, 21, 751-62

Donckner E.J. and G. Feichtinger (1993) "Cyclical Consumption Patters and Rational Addiction" American Economic Review, 83(1), 256-263

Dosi G. (1982) "Technological Paradigms and Technological Trajectories: A Suggested Interpretation of the Determinants and Directions of Technical Change" Research Policy, 12, 147-62

Douglas M. (1975) Implicit Meanings: Essays in Anthropology London: Routledge Kegan Paul 
Durlauf S.N. "Spillovers, Stratification and Inequality" European Economic Review, 38(3/4), 836-845

Duesenberry J.S. (1949) Income, Saving and the Theory of Consumer Behaviour Cambridge, Mass: Cambridge University Press

Farrell J.R. and G. Saloner (1985) "Standardization, Compatibility and Innovation", RAND Journal of Economics, 16, 70-82

Feichtinger G., A. Prskewetz, W. Herold and P. Zinner (1995) "Habit Formation with Threshold Adjustment: Addiction May Imply Complex Dynamics" Journal of Evolutionary Economics, 5, 157-172

Filser M. (1987) "Reperer l'Evolution des canaux de distribution" Revue Francaise de Gestion, 62, 90-96

Fine B. and E. Leopold (1993) The World of Consumption London: Routledge

Gaertner W. (1974) "A Dynamic Model of Inter-dependent Consumer Behaviour" Zeitschrift fuer Nationaloekonomie, 34, 327-44

Galbraith J.K. (1958) The Affluent Society Boston: Houghton Miflin

Galbraith J.K. (1987) A History of Economics: The Past as the Present London: Hamish Hamilton

Gintis H. (1974) "Welfare Criteria with Endogenous Preferences: The Economics of Education" International Economic Review, 15, 415-30

Gorman W.M. (1967) "Tastes, Habit and Choices" International Economic Review, 8, 218-22 
Granovetter M. (1978) "Threshold Models of Collective Behaviour" American Journal of Sociology, 83(6), 1420-1443

Granovetter M. and R. Soong (1986) "Threshold Models of Interpersonal Effects in Consumer Demand" Journal of Economic Behaviour and Organization, 7(1), 83-100

Hirsch S. (1997) Rich Man's, Poor Man's, and Every Man's Goods Tubingen: J.C.B. Mohr (Paul Siebeck)

Katz M. and C. Shapiro (1985) "Network Externalities, Competition and Compatibility" American Economic Review, 75, 424-440

Keilbach M. (1995) Network Externalities and Path Dependent Consumer Preferences IIASA Working Paper WP-95-97, Laxenburg, Austria

Kwasnicki W. (1995) Chance and Necessity in Industrial Development IIASA Working Paper, WP-95-65, Laxenburg, Austria

Liebenstein H. (1950) "Bandwagon, Snob and Veblen Effects in the Theory of Consumers' Demand" Quarterly Journal of Economics, 65, 183-207

Mansfield E. (1961) "Technical Change and the Rate of Imitation" Econometrica 29(4) 741-66

Marshall A. (1920) Principles of Economics, 8th Edition, London: MacMillan

Metcalfe J.S. and M. Gibbons (1986) "Technological Variety and the Process of Competition" Economie Appliqué, 39, 493-520

Nelson R.R. (1995) "Recent Evolutionary Theorizing about Economic Change" Journal of Economic Literature, 33,

Packard V. (1957) The Hidden Persuaders London: Longman 
Pasinetti, L.L. (1981) Structural Change and Economic Growth: A Theoretical Essay on the Dynamics of Wealth Creation, Cambridge: Cambridge U P

Pollak R.A. (1970) "Habit Formation and Dynamic Demand Functions" Journal of Political Economy, 78, 60-78

Prescott E. and M. Vischer (1977) "Sequential Location Among Firms with Foresight" Bell Journal of Economics, 8, 378-93

Priem R.L. (1992) "Industrial Organization Economics and Alderson's 'General Theory of Markets' " Journal of the Academy of Marketing Science 20(2), 135-141

Rogers E.M. Diffusion of Innovations, Third Edition, New York: The Free Press (first edition, 1962)

Schelling T. (1971) "Dynamic Models of Segregation" Journal of Mathematical Sociology, $1,143-96$

Schotter A. (1981) The Economic Theory of Social Institutions, New York : Cambridge University Press.

Silverberg G., G. Dosi and L. Orsenigo (1988) "Innovation, Diversity and Diffusion: A Self-Organization Model" Economic Journal 98, 1032-54

Steedman I. (1989) From Exploitation to Altruism London: Polity Press

Swann G.M.P. (1996) The Functional Form of Network Externalities Unpublished Paper, Manchester Business School, Manchester

Swann G.M.P. and M. Tavakoli (1994) "An Econometric Analysis of Television Viewing, and the Welfare Economics of Introducing an Additional Channel in the UK" Information Economics and Policy, 6, 25-51 
Veblen T. (1899) The Theory of the Leisure Class: An Economic Study of Institutions New York: MacMillan

Von Weizaecker C.C. (1971) "Notes on Endogenous Changes of Tastes" Journal of Economic Theory, 3, 345-72

Weidlich W. and M. Braun (1993) "The Master Equation Approach to Nonlinear Economic Processes" in U. Witt (Ed.) Evolution in Markets and Institutions. Heidelberg: Physica

Weise, P. (1992). "Evolution of a Field of Socioeconomic Forces", in U. Witt (ed.) Explaining Process and Change, Ann Arbor: Michigan University Press 


\section{Appendix}

In this appendix we present the derivation of the solution to equation 1 . The change in the probability that an agent consumes the good is given by

$$
\frac{d}{d t} p(s, t)=\int_{-\infty}^{\infty} F_{0}\left(s, s^{\prime}\right) p\left(s^{\prime}, t\right) d s^{\prime}-\alpha\left(p(s, t)-p_{0}(s)\right)
$$

In order to solve this equation we transform the two variables, $s$ and $t$. A Fourier transform on $s$ and a Laplace transform on $t$ yield the conjugate variables $k$ and $z$ :

$$
P(k, t)=\int_{-\infty}^{\infty} e^{i k s} p(s, t) d s
$$

and so

$$
P(k, z)=\int_{-\infty}^{\infty} e^{-i k s} \int_{0}^{\infty} e^{i z t} p(s, t) d t d s .
$$

We assume that the imaginary part of $z, \operatorname{Im}(z)>0$ to ensure convergence.

Integrating by parts with respect to $t$ and substituting for $d p(s, t) / d t$ gives:

$$
\begin{aligned}
P(k, z)=- & \frac{1}{i z} \int_{-\infty}^{\infty} e^{-i k s} p(s, 0) d s-\frac{1}{i z} \int_{-\infty}^{\infty} e^{-i k s} \int_{-\infty}^{\infty} e^{i z t} \int_{0}^{\infty} F_{0}\left(s-s^{\prime}\right) p\left(s^{\prime}, t\right) d s^{\prime} d s d t \\
& +\frac{1}{i z} \int_{0}^{\infty} e^{-i z t} \int_{-\infty}^{\infty} e^{i k s}\left(p(s, t)-p_{0}(s)\right) d s d t \\
= & -\frac{1}{i z} \mathcal{P}(k, 0)-\frac{\alpha}{z^{2}} P_{0}(k)+\frac{\alpha}{i z} P(k, z)-\frac{1}{i z} F_{0}(k) P(k, z)
\end{aligned}
$$

where

$$
\begin{aligned}
F_{0}(k) & =\int_{-\infty}^{\infty} e^{-i k s} F_{0}(s) d s \\
\mathcal{P}(k, 0) & =\int_{-\infty}^{\infty} e^{-i k s} p(s, 0) d s \\
P_{0}(k) & =\int_{-\infty}^{\infty} e^{-i k s} p_{0}(s) d s
\end{aligned}
$$

This can be re-arranged as

$$
P(k, z)\left(1-\frac{1}{i z}\left(\alpha-F_{0}(k)\right)\right)=-\frac{1}{i z} \mathcal{P}(k, 0)-\frac{\alpha}{z^{2}} P_{0}(k) .
$$

Thus

$$
P(k, z)\left(z^{2}+i z\left(\alpha-F_{0}(k)\right)\right)=i z \mathcal{P}(k, 0)-\alpha P_{0}(k)
$$


or

$$
P(k, z)=\frac{i z \mathcal{P}(k, 0)-\alpha P_{0}(k)}{z^{2}+i z\left(\alpha-F_{0}(k)\right)}
$$

To solve this we use the following manipulation: $\frac{A z+B}{z(z+C)}=\frac{X}{Z}+\frac{Y}{Z+C}=\frac{X Z+X C+Y Z}{Z(Z+C)}$ where $X+Y=A ; X C=B: X=B / C ; Y=A-B / C$. In our case, $A=i \mathcal{P}_{0}(k) ; B=$ $-\alpha P_{0}(k) ; C=i\left(\alpha-F_{0}(k)\right) ; X=i \alpha P_{0}(k) /\left(\alpha=F_{0}(k)\right)$ and $Y=i \mathcal{P}(k, 0)-\frac{i \alpha P_{0}(k)}{\alpha-F_{0}(k)}$. Thus we can write

$$
P(k, z)=\frac{i \alpha P_{0}(k)}{z\left(\alpha-F_{0}(k)\right)}+\frac{i\left(\alpha-F_{0}(k)\right) \mathcal{P}(k, 0)-i \alpha P_{0}(k)}{\left(z+i\left(\alpha-F_{0}(k)\right)\right)\left(\alpha-F_{0}(k)\right)}
$$

Solving as a differential equation, the particular solution for $P(k, t)$ will be a constant. (In the steady state $P(k, t)$ is a constant, since $P(s, t)$ will be a constant.) Thus since $P(k, z)=\int_{0}^{\infty} e^{i z t} P(k, t) d t$, we can see that $P(k, z)=C_{1} \int_{0}^{\infty} e^{i z t} d t$, which gives that $P(k, z)=C_{1}(-1 / i z)$. From equation A2, this gives that

$$
C_{1}=\frac{\alpha P_{0}(k)}{\alpha-F_{0}(k)}
$$

We can write the general solution as $P(k, t)=C_{2} e^{-D t}$. We assume, again to assure convergence, that $\operatorname{Re}(D)+\operatorname{Im}(z)>0$. By the same argument,

$$
\begin{aligned}
P(k, z) & =C_{2} \int_{0}^{\infty} e^{-D t} e^{i z t} d t \\
& =C_{2}(-1) /(i z-D) .
\end{aligned}
$$

From equation A2 we can see then that $D=\alpha-F_{0}(k)$ and that

$$
C_{2}=\frac{-\alpha P_{0}(k)+\left(\alpha-F_{0}(k)\right) \mathcal{P}(k, 0)}{\alpha-F_{0}(k)}
$$

Thus

$$
\mathcal{P}(k, t)=\frac{\alpha P_{0}(k)}{\alpha-F_{0}(k)}-\frac{\alpha P_{0}(k)-\left(\alpha-F_{0}(k)\right) \mathcal{P}(k, 0)}{\alpha-F_{0}(k)} e^{-\left(\alpha-F_{0}(k)\right) t} .
$$

